\title{
Nerve Growth Factor Enhances the Expression of the Cholinergic-Specific Ganglioside Chol-1 in Cocultures of Rat Septum and Hippocampus
}

\author{
Edmund A. Derrington, *Beat H. Gähwiler, and Victor P. Whittaker \\ Arbeitsgruppe Neurochemie, Max-Planck-Institut für biophysikalische Chemie, Göttingen, F.R.G.; and \\ *Institut für Hirnforschung, Universität Zürich, Zürich, Switzerland
}

\begin{abstract}
Cocultures of septal and hippocampal tissues taken from 6- to 7-day-old rats were maintained in culture for up to 30 days in the presence and absence of nerve growth factor (NGF), and their Chol-1 contents determined at varying time intervals by a modified enzyme-linked immunosorption assay (ELISA). The major brain gangliosides were determined densitometrically after spraying chromatograms with resorcinol reagent. There was little change in the contribution of the major gangliosides to the total ganglioside content of the explants either with time or the presence or absence of NGF, the only exception being an NGF-insensitive fall in the contribution of GMI to about $60 \%$ of its initial value at 20 and 30 days. By contrast, the concentration of Chol-1 expressed either per unit weight of ganglioside sialic acid or protein increased considerably in culture and this increase was enhanced by NGF. The effect of NGF resembles that on other cholinergic markers, choline acetyltransferase and acetylcholinesterase, and may be attributed to an NGF-stimulated hippocampal ingrowth of cholinergic fibres and enhanced survival of cholinergic septal neurons. The Chol-1 concentration finally attained in the presence of NGF and the time course of its increase parallel those previously found in vivo and indicate the potential usefulness of septal-hippocampal cocultures for investigating the function of Chol-1. Key Words: Septal-hippocampal cocultures-Expression of Chol-1-Nerve growth factor. Derrington E. A. et al. Nerve growth factor enhances the expression of the cholinergic-specific ganglioside Chol- 1 in cocultures of rat septum and hippocampus. J. Neurochem. $55,2132-2134(1990)$.
\end{abstract}

Previous studies have shown that a group of gangliosidic antigens, collectively designated Chol-1, and originally detected in the cholinergic electromotor innervation of the electric ray, Torpedo marmorata, are also present in the mammalian central and peripheral nervous systems, where they are specific for cholinergic neurons (Jones et al., 1981; Richardson et al., 1982; Ferretti and Borroni, 1986; Derrington et al., 1989; Giuliani et al., 1990). These antigens are first detected relatively late in development in both the central and peripheral nervous systems (Derrington and Borroni,
1990), a result suggesting that their appearance represents a membrane modification related to the stabilization or survival of cholinergic synapses. Thus, in the rat hippocampus, Chol1 is first detected between the 10th and 20th day of postnatal life, reaching its adult value at 50 days; by contrast, choline acetyltransferase (ChAT) first appears between 5 and 10 days and reaches its adult value at 30 days (Derrington and Borroni, 1990).

Neurites of septal neurons have been shown to grow out and form cholinergic synapses with hippocampal cells when septal and hippocampal explants from neonatal rats are cocultured in vitro. The expression of cholinergic function as measured by the appearance of ChAT is enhanced by the addition of nerve growth factor (NGF) to the culture medium (Gähwiler and Brown, 1987; Gähwiler et al,, 1990). We wished to investigate (a) the time-course of expression of Chol1 in the hippocampal explants in order to compare this with events in vivo, and (b) the response of Chol-1 to NGF. It was felt that if the Chol-1 content of the explants were enhanced by NGF, the in vitro hippocampus could provide a useful tool for investigating the function of Chol-1.

\section{MATERIALS AND METHODS}

\section{Tissue culture}

Cocultures of hippocampal and septal slices (Gähwiler, 1981) were prepared in Zürich from 5- to 6-day-old rats and grown in culture medium by means of the roller-tube technique with or without NGF $(100 \mathrm{ng} / \mathrm{ml})$ for up to 30 days. The culture medium consisted of horse serum (25\%), basal Eagle's medium supplemented with Earle's salt mixture (50\%), and Earle's balanced salt solution (25\%), and was supplemented with glucose to a final concentration of $6.5 \mathrm{~g} / \mathrm{L}$. After 10,20 , or 30 days cultures were fixed for $1 \mathrm{~h}$ in $4 \%$ paraformaldehyde and after washing in phosphate-buffered
Received August 8, 1990; accepted August 16, 1990.

Address correspondence and reprint requests to Dr. V.P. Whittaker at AG Neurochemie, MPI für biophysikalische Chemie, Postfach 2841, D-3400 Göttingen, F.R.G.
Abbreviations used: ChAT, choline acetyltransferase; ELISA, enzyme-linked immunosorption assay; NGF, nerve growth factor. 
saline mailed to Göttingen for ganglioside analysis. Cultures were scraped from the coverslips on which they were grown into $1.2 \mathrm{ml}$-capacity Eppendorf centrifuge tubes using a dissection microscope. The tissue was pelleted by centrifugation at $10,000 \mathrm{~g}$ for $5 \mathrm{~min}$ and the supernatant decanted. An Eppendorf table-top centrifuge was used throughout. The pellets were frozen in liquid nitrogen and lyophilized.

\section{Analyses}

Extraction of gangliosides. Gangliosides were extracted from the lyophilized pellets by the method of Tettamanti et al. (1973), modified for very small (10 mg or less) tissue samples. Potassium phosphate buffer $(10 \mathrm{mM}, \mathrm{pH} 6.8)(100 \mu \mathrm{l})$ and tetrahydrofuran $(400 \mu \mathrm{l})$ were added to an Eppendorf tube containing lyophilized tissue. The tissue was suspended by shaking for $30 \mathrm{~s}$ in a vortex mixer and then sonicated for 2 min at room temperature with a Branson B 15 probe sonifier equipped with a standard microprobe at a frequency of 20 $\mathrm{kHz}$ and a power setting of $2-3$. Insoluble material was pelleted by centrifugation for $10 \mathrm{~min}$ at $10,000 \mathrm{~g}$ and the supernatant transferred to a 2-ml-capacity Eppendorf tube. This extraction procedure was repeated three times. Diethyl ether ( $30 \%$ of the total supernatant volume) was added to the pooled supernatants, the whole was shaken for $2 \mathrm{~min}$ in a vortex mixer and then centrifuged at $10,000 \mathrm{~g}$ for $10 \mathrm{~min}$ to promote the separation of the phases. The aqueous (lower) phase was removed using a Pasteur pipette and stored. A second extraction of the ether phase was performed as described above after adding water ( $10 \%$ by volume) and shaking again for 2 min in a vortex shaker. The two aqueous phases were pooled and the ether removed by evaporation in a stream of nitrogen gas. When organic solvents were no longer detectable by smell, the contents of the tubes were dialysed for $16 \mathrm{~h}$ against distilled water ( 5 L, 2 changes).

The dialysed ganglioside fractions were lyophilized and gangliosides solubilized in $200 \mu \mathrm{l}$ of chloroform/methanol/ $\mathrm{H}_{2} \mathrm{O}$ mixture in the ratio 100:50:10 by volume.

Chol-1. The concentration of Chol-1 present in ganglioside fractions was determined by means of a modified enzymelinked immunosorption assay (ELISA) (Derrington and Borroni, 1990) which involved applying anti-Chol-1 antiserum, enzyme-linked second antibody and enzyme substrate directly to TLC plates and evaluating the colour intensities densitometrically. A commercial polysialoganglioside fraction, enriched $\sim 40$-fold in Chol-1 relative to whole brain gangliosides (Dr. Pallmann KG, Munich, F.R.G.) and containing it in about $1 \%$ concentration, served as a standard. One unit of Chol-1 was defined as the amount in $100 \mathrm{ng}$ of the fraction.
Sialic acid. Ganglioside-bound sialic acid was assayed by the method of Svennerholm (1957).

Other gangliosides. In one experiment, the relative concentrations of the major brain gangliosides were determined after separation by TLC and spraying with a resorcinol reagent (Derrington and Borroni, 1990). The linearity of the chemical staining was established using various concentrations of a standard preparation of rat brain gangliosides. The identity of the various gangliosides was determined by comparing their $R_{\mathrm{f}}$ values with those of pure samples of GM1, GD la, GD 1b, and GT1b (kindly provided by Dr A. Giuliani, University of Milan, Italy).

Protein analysis. The tissue pellets remaining from the ganglioside extraction were dried in a nitrogen stream, dissolved in $0.1 M \mathrm{NaOH}$, and their protein content determined using the bicucculine method (Pierce). Though this procedure suffered from the problem that some lipophilic proteins would have been extracted with the gangliosides, it was impossible to take a homogeneous sample for protein estimation at an earlier stage because the tissue had been fixed in paraformaldehyde.

\section{RESULTS}

Table 1 shows that cultures grown in the presence of NGF and those in its absence both show a slight increase in sialic acid per milligram of protein during the period in culture. This increase is slightly greater in NGF-treated cultures than controls. There is very little change in the relative contribution of the major gangliosides to the total ganglioside content of the explants either with time or the presence or absence of NGF. The only relatively large change occurs in the concentration of GM1 which falls from 14 and $15 \%$ in treated and control cultures, respectively, to $9 \%$ of the total mixture at 20 and 30 days. By contrast, the concentration of Chol-1 expressed per microgram of ganglioside sialic acid (Table 1, last column) or per milligram of protein (Fig. 1) shows a considerable increase during development in culture. Expressed per microgram of sialic acid (Table 1), it nearly doubles in controls and rises more than $300 \%$ in cultures treated with NGF. This $300 \%$ increase is similar to that shown by Chol-1 in the hippocampus during a similar period of development in vivo (Derrington and Borroni, 1990). Expressed per milligram of protein (Fig. 1), the effect of NGF is even greater $(400 \%$ at 30 days), greatly outstripping that of the major gangliosides over the same period ( $40 \%$ in NGF-treated cultures and $20 \%$ in controls).

TABLE 1. Effect of NGF on explant ganglioside content and distribution

\begin{tabular}{|c|c|c|c|c|c|c|c|}
\hline \multirow{2}{*}{$\begin{array}{l}\text { Time in } \\
\text { culture } \\
\text { (days) }\end{array}$} & \multirow[b]{2}{*}{$\mathrm{NGF}^{a}$} & \multirow{2}{*}{$\begin{array}{l}\text { Ganglioside sialic acid } \\
(\mu \mathrm{g} / \mathrm{mg} \text { of protein })^{b}\end{array}$} & \multicolumn{4}{|c|}{$\begin{array}{c}\text { Distribution of sialic acid among major } \\
\text { gangliosides }(\%)\end{array}$} & \multirow{2}{*}{$\begin{array}{l}\text { Chol-1 content } \\
(\mathrm{U} / \mu \mathrm{g} \text { of sialic acid })^{b}\end{array}$} \\
\hline & & & GMI & GDla & GD $1 b$ & GT1b & \\
\hline \multirow[t]{2}{*}{10} & - & $5.0 \pm 0.4$ & 15 & 37 & 19 & 28 & $1.33 \pm 0.44$ \\
\hline & + & $4.7 \pm 0.1$ & 14 & 41 & 17 & 28 & $1.34 \pm 0.52$ \\
\hline 20 & - & $5.6 \pm 1.5$ & 9 & 37 & 23 & 31 & $1.71 \pm 0.19$ \\
\hline \multirow[t]{2}{*}{30} & - & $5.9 \pm 0.2$ & 9 & 38 & 21 & 32 & $2.54 \pm 0.73$ \\
\hline & + & $6.7 \pm 0.3$ & 9 & 37 & 22 & 32 & $4.08 \pm 0.73$ \\
\hline
\end{tabular}

For definition of unit of Chol-1, see text.

${ }^{a}$ NGF present (+); NGF absent (-).

${ }^{b}$ Data are mean \pm SD values of three experiments. 


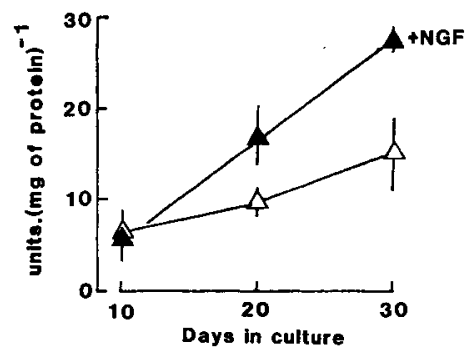

FIG. 1. Chol-1 content of explants (ordinate) plotted as a function of the time in culture (abscissa) and the effect of NGF on this. Open triangles, no supplement; filled triangles, supplemented with NGF; values are means \pm SD (bars) of three experiments. For definition of unit of Chol-1 see text.

\section{DISCUSSION}

In vivo, the expression of the Chol-1 gangliosides in the hippocampus is an event which occurs late during synaptogenesis. Quantitative analysis has shown that it parallels the increase in expression of ChAT though lagging behind the latter by about 10 days (Derrington and Borroni, 1990). This result was interpreted to mean that the expression of Chol1 is an event occurring late in synaptogenesis. Similarly, in culture Chol-1 is expressed after the other major gangliosides, and the concentration of Chol-1 per milligram of protein increases much more rapidly than that of the major brain gangliosides at this late stage in development. Treatment of the cultures with NGF, which is known to be important both for the stimulation of cholinergic differentiation and as a survival factor for cholinergic neurons (Gähwiler and Brown, 1987; Gähwiler et al., 1990), exacerbates the increases in concentration of Chol-1 per milligram of protein to rates of increase which are similar to those which occur in the hippocampus during development in vivo. Thus, the effect of NGF resembles that on other cholinergic markers, ChAT and acetylcholinesterase, as seen after four weeks in vitro (Gähwiler et al., 1990), and may be attributed to an NGFstimulated hippocampal ingrowth of cholinergic fibres and enhanced survival of cholinergic septal neurons. Unfortunately, the present study does not allow us to decide whether the effect of NGF is the result of an increase in the total number of cholinergic terminals present in the cultures or in the quantity of Chol-1 in each terminal. Nevertheless, it appears that the cocultures of septal and hippocampal brain slices provide a promising model system in which to investigate the function of Chol-1.

Acknowledgment: This work was supported by grants (to V.P.W.) from the Deutsche Forschungsgemeinschaft (grant no. Wh 1/5-2) and Fidia Pharmaforschung GmbH and by the Swiss National Science Foundation (to B.H.G.).

\section{REFERENCES}

Derrington E. A. and Borroni E. (1990) The developmental expression of the cholinergic-specific antigen Chol-1 in the central and peripheral nervous system of the rat. Dev. Brain Res. 52, 131-140.

Derrington E. A., Masco D., and Whittaker V. P. (1989) Confirmation of the cholinergic specificity of the Chol- 1 gangliosides in mammalian brain using affinity-purified antisera and lesions affecting the cholinergic input to the hippocampus of rat. $J$. Neurochem. $53,1686-1692$.

Ferretti P. and Borroni E. (1986) Putative cholinergic-specific gangliosides in guinea-pig forebrain. $J$. Neurochem. 46, 1888-1894.

Gähwiler B. H. (1981) Organotypic monolayer cultures of nervous tissue. J. Neurosci. Methods 4, 329-342.

Gähwiler B. H. and Brown D. A. (1987) Muscarine affects calciumcurrents in rat hippocampal pyramidal cells in vitro. Neurosci. Lett. 76, 301-306.

Gähwiler B. H., Rietschin L., Knöpfel R., and Enz A. (1990) Continuous presence of nerve growth factor is required for maintenance of cholinergic septal neurons in organotypic slice cultures. Neuroscience 36, 27-31.

Giuliani A., Calappi E., Borroni E., Whittaker V. P., Sonnino S., and Tettamanti G. (1990) Further studies on the gangliosidic nature of the cholinergic-specific antigen, Chol-1. Arch. Biochem. Biophys. 280, 211-216.

Jones R. T., Walker J. H., Richardson P. J., Fox G. Q., and Whittaker V. P. (1981) Immunohistochemical localization of cholinergic nerve terminals. Cell Tiss. Res. 218, 355-373.

Richardson P. J., Walker J. H., Jones R. T., and Whittaker V. P. (1982) Identification of a cholinergic-specific antigen Chol-1 as a ganglioside. $J$. Neurochem. 38, 1605-1614.

Svennerholm L. (1957) Quantitative estimation of sialic acids. II. A colorimetric resorcinol-hydrochloric acid method. Biochim. Biophys. Acta 24, 604-611.

Tettamanti G., Bonali F., Marchesini S., and Zambotti V. (1973) A new procedure for the extraction, purification and fractionation of brain gangliosides. Biochim. Biophys. Acta 296, 160-170. 